\title{
HUMOR SEBAGAI BENTUK PELANGGARAN MAKSIM KERJA SAMA DALAM ANIMASI SAIKI KUSUO NO PSINAN
}

\author{
Eka Triyana
}

\author{
312201500546@mhs.dinus.ac.id \\ Universitas Dian Nuswantoro
}

\begin{abstract}
This study aims to describe the occurrence of humor based on the cooperative principles theory by Grice (1975) and the theory of incongruity about the use cooperative principle violations in the humor of Saiki Kusuo no Psinan animation. The paradigm of this research is qualitative research with a pragmatic approach. The data source of this research is the Saiki Kusuo no Psinan animation. The data were in the form of 4 utterances containing humor. The utterances were then analyzed based on Grice's cooperative principles to look for violations of the cooperative principles. The utterances were also analyzed by using the theory of incongruity to see the humor formed from the utterances of the character. From the results of the analysis, it is concluded that humor occurs because of the violation of cooperative principles caused by the incongruent situation. In 4 utterances, there are various violations of the cooperative principles. Those are: 3 maxim of quantity violations, 1 maxim of quality violation, 4 maxim of relevance violations, and 4 maxim of manner violations. In addition, there are also 3 utterances that violated 2 maxims at once, i.e. 1 violation of maxim of quantity and relevance, 1 violation of maxim of quality and quantity, 1 violation of maxim of manner and relevance. These 4 utterances cause an incongruent situation that triggers humor.
\end{abstract}

Keywords: Cooperative Principles, Humor, Pragmatics.

Yule dalam Saifudin (2005:17) menjabarkan pragmatik dengan empat definisi, (1) yaitu pragmatik adalah ilmu yang mengkaji maksud penutur; (2) yaitu pragmatik mengkaji makna menurut konteksnya; (3) yaitu pragmatik tentang bagaimana apa yang disampaikan itu lebih banyak dari yang dituturkan; (4) yaitu pragmatik merupakan bidang yang mengkaji bentuk ungkapan menurut jarak hubungan. Sehingga disimpulkan bahwa pragmatik adalah suatu ilmu yang mempelajari mengenai maksud penutur dan yang ditafsirkan oleh mitra tuturnya. Dalam pragmatik dijabarkan mengenai aturan-aturan yang harus dipatuhi oleh para penutur agar apa yang dituturkan dapat diterima secara efektif oleh mitra tuturnya. Aturan-aturan 
tersebut disebut dengan prinsip kerja sama atau maksim kerja sama, namun pelanggaran terhadap prinsip kerja sama justru dapat menimbulkan humor. Selain prinsip kerja sama, terdapat pula prinsip kesopanan yang harus dipatuhi oleh para penutur. Dalam pragmatik, ada dua hal yang menjadi titik perhatian, yakni penggunaan bahasa dan konteks tuturan. Penggunaan bahasa maksudnya berhubungan dengan fungsi bahasa karena selalu saja ada masalah dalam sebuah bahasa. Penutur bahasa mungkin saja terjebak pada suasana kebahasaan yang tidak efektif. Suatu kondisi bahasa yang mengakibatkan penutur bahasa mengalami kesalahpahaman dalam suasana dan konteks tuturan (Wijana, 1996: 32).

Bahasa merupakan alat komunikasi yang digunakan oleh manusia. Di dalam penggunaan bahasa dapat juga digunakan sebagai humor. Wijana (2004: 12) bahwa bahasa yang dapat digunakan sebagai sarana pengungkap humor merupakan hasil budaya masyarakat, sehingga identitasnya sebagai humor hanya dapat diberi makna sepenuhnya oleh masyarakat itu sendiri. Keberadaan bahasa dapat memperlancar dan mempermudah proses komunikasi dalam masyarakat.

Wijana (2004:37) menyatakan bahwa humor pada hakikatnya adalah rangsangan yang menyebabkan seseorang tertawa atau tersenyum dalam kebahagiaan. Dalam kaitan ini ada tiga aspek yang layak diperhatikan, yakni tindakan verbal atau nonverbal yang merupakan stimulusnya, aktivitas kognitif dan intelektual sebagai alat persepsi dan evaluasi rangsangan itu, dan respon yang dinyatakan dengan senyum dan tawa.

\section{METODE PENELITIAN}

\section{Sumber Data}

Sumber data dalam penelitian ini animasi yang berjudul Saiki Kusuo no Psi nan. Sumber data ini dipilih karena di dalam animasi tersebut terdapat humor-humor yang mewakili pelanggaran maksim kerja sama untuk diteliti. 
Eka Triyana, Humor Sebagai Bentuk Pelanggaran Maksim Kerja Sama dalam Animasi Saiki Kusuo No Psinan

\section{Satuan Analisis}

Data yang di analisi berupa ungkapan-ungkapan dari tokoh yang terdapat dalam animasi Saiki Kusuo no Psi nan karya Shuuichi Asou yang mengandung humor. Tuturan yang mengandung humor dianalisis dengan menggunakan teori Grice tentang prinsip kerja sama (1975).

Saiki Kusuo no Psi nan merupakan serial animasi karya Shuuichi Asou yang telah ditayangkan pada televisi Jepang maupun internet. Kepopuleran animasi ini terletak pada humor karakternya yang diceritakan pada kehidupan yang dijalani anak SMA. Namun bedanya dalam animasi ini karakter utamanya memiliki kekuatan spiritual seperti, telekomunikasi, telepati, teleport, memindahkan barang dan lain-lain. Kekuatan ini dia gunakan untuk memanipulasi teman-teman nya dan lingkungan sekitarnya untuk membuatnya terlihat normal. Dalam kesehariannya dia ditemani oleh teman-teman yang memiliki tuturan-tuturan untuk membuat keseharian dari Saiki sebagai karakter utama dengan humor.

\section{Teknik Pengumpulan Data}

Teknik pengumpulan data dalam penelitian ini adalah :

1. Menggunakan teknik simak-catat untuk menemukan percakapan yang mengandung humor dengan menggunakan teori inkongruitas;

2. Mengkategorikan data yang terkumpul dengan menggunakan teori prinsip kerjasama Grice (1975).

\section{Teknik Analisis Data}

1. Data yang sudah terkumpul dan terkategorisasi disajikan dalam bentuk kutipan percakapan.

2. Mengidentifikasi humor dengan analisis konteks dan teori inkongruitas. 
3. Menganalisis tuturan humor dengan analisis prinsip kerja sama Grice (1975) untuk menekankan pelanggaran prinsip kerja sama yang menyebabkan terjadinya humor.

\section{HASIL DAN PEMBAHASAN}

Dalam animasi Saiki Kusuo no Psinan telah ditemukan 15 data kemudian data dari tuturan-tuturan tokoh yang mengandung pelanggaran prinsip kerja sama dan memberikan efek humor dalam tiap-tiap tuturan. Setelah tuturan tersebut dikumpulkan dan dianalisis, ditemukan 4 jenis pelanggaran prinsip kerja sama dalam maksim yang terdiri dari : 1) Maksim Kuantitas, 2) Maksim kualitas, 3) Maksim Relevansi, dan terakhir 4) Maksim Cara. Adapun hasil dari data-data tersebut adalah sebagai berikut :

\section{Humor yang ditimbulkan oleh pelanggaran prinsip kerjasama Maksim Kuantitas}

\section{Percakapan 1}

何だよ！お前までママの味方か!?

"nanda yo ! omae made mama no mikata ka !?"

'Apa?! kau pun memihak ibumu ?!'

お前が食ってる飯だって僕が上司の靴ぺロペロなめて稼いだ 金だぞ!

"omae ga kutteru gohan datte boku ga joushi no kutsu pero pero namete kaseida kane da zo !"

'Makanan yang kau makan itu, aku beli dengan uang yang kudapat dari Menjilat sepatu bos ku!'

(父) いやあ高い靴は... 味が違うなあ〜

"iyaa takai kutsu ha .. aji ga chigau na $\sim$ “

'wah sepatu mahal rasanya berbeda ya!'

(楠雄) なんだ 大好物じゃないか

"nanda daikoubutsu janai ka"

'oh jadi kau hobi makan sepatu' 
Eka Triyana, Humor Sebagai Bentuk Pelanggaran Maksim Kerja Sama dalam Animasi Saiki Kusuo No Psinan

Dalam tuturan 1, terjadi di ruang makan antara ayah dan saiki. Mereka adalah Keluarga dan memiliki hubungan sebagai ayah dan anak. Ayah yang merasa lelah karena berdebat dengan sang ibu meminta Saiki menggunakan kekuatannya untuk mengubah Steak sepatu yang disajikan ibu menjadi steak daging sapi normal. Namun permintaan tersebut tidak didengarkan oleh Saiki meskipun ayah meminta dan memelas. Saiki berfikir jika dia menuruti keinginan ayah nya, maka ayah nya akan menjadi seseorang yang tidak berguna karena bergantung kepada kekuatan yang Saiki miliki. Namun ayah yang sudah tidak mampu lagi menahan amarah, meledak dan menjelaskan bahwa semua makanan yang ada di meja makan adalah hasil dari kerja keras nya seharian. Namun setelah dia sampai di rumah tidak ada yang menghargai kerja kerasnya.

Dalam percakapan 1 ditemukan pelanggaran maksim kuantitas. tuturan yang mangandung pelanggaran maksim kuantitas adalah "omae ga kutteru gohan datte boku ga joushi no kutsu pero pero namete kaseida kane da zo !’ yang berarti 'Makanan yang kau makan itu, aku beli dengan uang yang kudapat dari Menjilat sepatu bos ku !', dalam tuturan tersebut ayah menjelaskan informasi yang tidak perlu disampaikan atau bertele-tele kepada Saiki.

Dalam percakapan 1 melanggar maksim kuantitas karena ayah berharap dengan melebih-lebihkan informasi tersebut bermaksud agar Saiki lebih menghargai dirinya yang telah berkerja keras dan agar mau menggunakan kekuatan yang dimiliki oleh Saiki untuk mengabulkan keinginannya. Namun hal tersebut tidak sesuai yang diharapkan Ayah dan justru mendapatkan jawaban yang santai dari Saiki sehingga menimbulkan humor karena sang ayah dalam tuturan tersebut juga menginformasikan bahwa perkerjaan yang dilakukannya untuk mendapatkan uang adalah dengan menjilat sepatu bosnya. jika ayah menjelaskan tuturan tersebut dengan tuturan 'makanan yang kau makan itu dibeli dengan uang hasil kerja kerasku, seharusnya kamu lebih menghargai ayah' maka hal tersebut tidak akan menjadi lucu.

Dengan tuturan tersebut ayah berharap jika Saiki mengerti tentang makanan yang dimakannya saat itu adalah hasil dari kerja kerasnya. namun harapan ayah agar 
Saiki mengubah steak sepatu menjadi steak daging tidak digubris sehingga ayah merasa kecewa. Tuturan tersebut diucapkan sang ayah karena merasa kecewa dengan Saiki yang tidak mau memenuhi keinginannya.

\section{Humor yang ditimbulkan oleh pelanggaran prinsip kerjasama Maksim Kualitas}

\section{Percakapan 2}

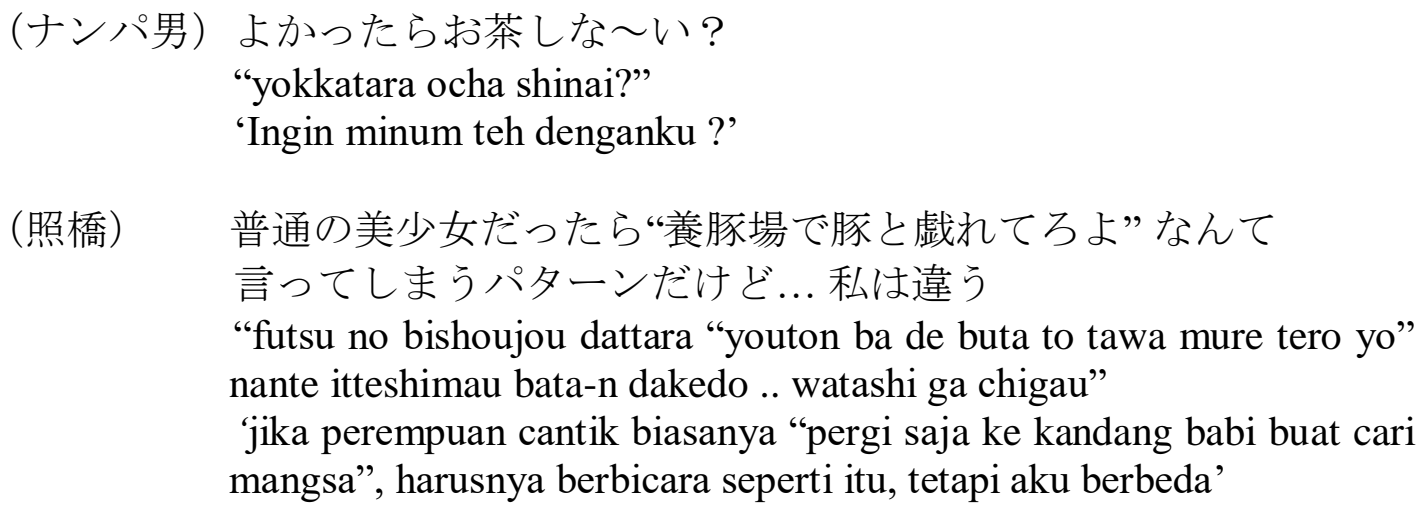

Dalam percakapan 2, Teruhashi merupakan siswi SMA dengan kecantikan yang seperti malaikat. Nanpa otoko atau orang asing adalah tokoh pembantu dalam tuturan ini untuk memperkenalkan Teruhashi kepada para penonton. Hubungan Teruhashi dan Nanpa otoko adalah tidak saling mengenal. Teruhashi yang sedang berjalan-jalan ditempat perbelanjaan memperkenalkan diri kepada para penonton sebagai sosok seseorang yang cantik dan selalu mendapat perhatian semua orang. Perhatian tersebut menurutnya adalah hal yang wajar karena dia memiliki penampilan yang menarik. Dia memperkenalkan diri sebagai sosok yang tidak sombong meskipun memiliki kecantikan yang menawan semua orang disekitarnya.

Dalam percakapan 2 melanggar maksim kualitas. Tuturan yang mengandung pelangaran maksim kualitas adalah "futsu no bishoujou dattara "youton ba de buta to tawa mure tero yo" nante itteshimau bata-n dakedo .. watashi ga chigau" yang berarti "jika perempuan cantik biasanya "pergi saja ke kandang babi buat cari mangsa", harusnya berbicara seperti itu, tetapi aku berbeda'. Tuturan tersebut tidaklah sesuai dengan ucapan yang diberikan Teruhashi di awal, Teruhashi 
Eka Triyana, Humor Sebagai Bentuk Pelanggaran Maksim Kerja Sama dalam Animasi Saiki Kusuo No Psinan

menjelaskan bahwa dirinya tidaklah seorang yang sombong akan penampilan yang dimilikinya kepada penonton. Namun saat menjelaskan cara penolakan wanita cantik, hal tersebut berdasarkan atas pendapat dari dirinya sendiri bahwa penolakan wanita cantik akan terdengar seperti data tuturan tersebut. Kelucuan tuturan tersebut timbul ketika Teruhashi sebagai wanita cantik mengatakan bahwa dirinya tidaklah sombong, namun secara tidak langsung tuturan tersebut juga mengungkapkan sisi kesombongan dari Teruhashi sendiri, karena dia juga menggatakan perandaian menggunakan pendapatnya sendiri sedangkan untuk menutupi kesombongannya dia menolak perandaian yang dia ucapkan dengan kata 'saya berbeda'.

Dalam percakapan 4, Teruhashi berharap kepada para penonton bahwa dia tidak disamakan dengan wanita cantik pada umumnya. Karena apa yang ada dipikiran wanita cantik saat diajak oleh seseorang yang tidak dikenal adalah penolakan yang kasar karena berani mengajak wanita cantik tanpa ada hubungan pertemanan atau hubungan lainnya. Namun dalam tuturan tersebut tidaklah sesuai dengan harapan karena dalam tuturan tersebut Teruhashi digambarkan sebagai seseorang yang sombong namun dirinya sendiri menolak karakter dari dirinya tersebut. Jika Teruhashi, mengatakan permisalan yang lebih lembut, dan memberikan informasi yang jelas, maka tidaklah menjadi lucu tuturan yang diungkapkan teruhashi, seperti, 'jika orang cantik biasanya akan menolak "maaf saya tidak kenal dengan kamu'. Maka hal tersebut tidaklah memicu tawa dan terdengar biasa saja.

\section{Humor yang ditimbulkan oleh pelanggaran prinsip kerjasama Maksim Relevansi}

\section{Percakapan 3}

(高橋）＼cjkstart仮病だよバカ！ふざけんなマジで！オエ〜ッ

"Kebyou da yo baka!. Fuzaken na majide ! Oeee"

'Aku sakit tipuan, bodoh! yang benar saja! Hueghh!'

なんで男とキスしなきやなんねえんだよ

"Nande otoko to kisu shinakya nan nendayo"

'Kenapa aku harus mencium pria?!'

(燃堂） まあ、俺様のファーストキスに免じて勘弁してくれや 
"maa, ore sama no faasuto kisu ni menjite kanben shite kureya"

'Itu juga ciuman pertamaku, kita anggap saja impas.'

Dalam percakapan 3, percakapan terjadi di ruang UKS antara Saiki, Nendou dan Takahashi. Mereka adalah murid dari Sekolah PK yang saat itu sedang mengadakan upacara penerimaan murid baru. Saiki sebagai tokoh utama memiliki rahasia karena memiliki kemampuan telekinesis seperti membaca pikiran, berpindah tempat, dan kemampuan lainnya. Nendou sebagai petutur merupakan murid biasa dari sekolah PK, dan juga merupakan teman sekelas Saiki. Takahashi sebagai mitra tutur, merupakan teman sekelas dari Nendou dan Saiki. Tuturan diatas terjadi ketika Nendou membantu dan membawa Takahashi ke UKS karena tiba-tiba saja dia pingsan dalam acara penerimaan murid baru. Sesampainya di ruang UKS ternyata tidak ada petugas atau guru di dalamnya. Karena Takahashi masih pingsan Nendou memutuskan untuk memberikan bantuan pernafasan kepada Takahashi agar siuman. Akan tetapi setelah melakukan bantuan pernafasan melalui mulut, tiba-tiba saja Takahashi bangun dan marah kepada Nendou. Ternyata Takahashi hanya berpurapura pingsan untuk menghindari upacara penerimaan murid. Umumnya upacara penerimaan murid baru diadakan untuk memberikan selamat karena diterima di sekolah. Upacara penerimaan biasanya diisi dengan sambutan kepala sekolah serta pidato dari perwakilan murid yang berprestasi. Karena hal tersebut memakan waktu yang cukup lama, sebagian murid melakukan tindakan-tindakan agar terhindar dari upacara penerimaan tersebut seperti yang dilakukan oleh Takahashi.

Dalam percakapan 3, terjadi pelanggaran maksim relevasi. Pelanggaran maksim relevansi terdapat dalam tuturan "maa, ore sama no faasuto kisu ni menjite kanben shite kureya" yang berarti "Itu juga ciuman pertamaku, kita anggap saja impas.' Dalam data tersebut tuturan yang diucapkan oleh Nendou melanggar maksim relevansi karena tuturan yang diungkapkan tidak relevan dengan pertanyaan. Dalam tuturan tersebut Nendou mengatakan bahwa ciuman yang dilakukan terhadap Takahashi merupakan ciuman pertamanya, sedangkan tuturan tersebut tidak menjawab apa yang menjadi topik pembicaraan. Tuturan tersebut menimbulkan kelucuan karena apa yang dikatakan oleh Nendou adalah sesuatu yang diluar 
Eka Triyana, Humor Sebagai Bentuk Pelanggaran Maksim Kerja Sama dalam Animasi Saiki Kusuo No Psinan

perkiraan, tuturan tersebut membuat Takahashi salah paham dan mual karena ucapan yang dikatakan Nendou tidak sesuai dengan apa yang diharapkan. Tuturan tersebut tidak seharusnya diucapkan karena akan menyakiti hati Takahashi.

Dalam percakapan 3, Takahashi menanyakan kepada Nedou kenapa dia harus mencium pria dalam keadaan pura-pura pingsan. Takahashi berharap Nendou memberikan jawaban yang dapat diterimanya. Namun Nendou malah memberikan jawaban yang tidak sesuai dan malah menambah penderitaan Takahashi. Takahashi meminta jawaban kenapa dia harus dicium saat berpura-pura pingsan. Jika Nendou sebagai petutur menjawab 'karena tiba-tiba saja kamu pingsan, maka secara tidak sadar aku membantu dirimu dengan nafas buatan agar kamu segera siuman'. Maka hal tersebut tidak akan memicu humor.

\section{Humor yang ditimbulkan oleh pelanggaran prinsip kerjasama Maksim Cara}

\section{Percakapan 4}
(鳥束) 斉木さんの真横にはケツ丸出しの...つてそんなことより 師 匠！どうかオレを弟子にしてくださいっス
"Saiki-san no mayoko ni ha ketsu maru dashi no Tte sonna koto yori shishou! Dou ka, ore wo deshi ni shite kudasai ssu"
'Di sebelah kananmu ada bokong bugil yang ... Daripada itu, Guru,
(楠雄） そんなことより,ケツ丸出しってなんだ
"sonna koto yori, ketsu maru dashitte nanda"
'Daripada itu, apa yang kaumaksud dengan bokong bugil?'

Dalam percakapan 4, terjadi di kamar tidur Saiki. Saiki merupakan tokoh utama yang memiliki kekuatan telekinesis. Sedangkan Toristuka merupakan seseorang yang memiliki kekuatan melihat dan dapat berbicara dengan hantu. Hubungan tokoh dalam dialog ini adalah orang asing. karena Saiki dan Toritsuka sama-sama belum saling kenal dan baru pertama kali bertemu dalam kesempatan tersebut. Percakapan terjadi beberapa saat setelah Saiki menerima sebuah amplop berisikan rahasia yang dia miliki dan permintaan untuk menjadikan murid pengirim surat. Hal tersebut membuat Saiki terkejut karena tidak ada seseorang pun yang mengetahui kemampuan yang 
dimilikinya selain keluarganya. Namun sebelum Saiki menggunakan kekuatannya untuk mencari pengirim surat, Toritsuka kemudian muncul dan memperkenalkan diri sebagai pengguna kekuatan yang dapat berkomunikasi dengan hantu. Toritsuka yang sudah memastikan bahwa Saiki tidak dapat melihat hantu, mulai menjelaskan bahwa hantu sering berkumpul untuk mengamati cenayang (pengguna telekinesis), dan sekarang telah ada 15 hantu yang berada dikamar tidur Saiki.

Dalam percakapan 4 ditemukan pelanggaran maksim cara. Pelanggaran tersebut dapat ditemukan dalam tuturan "Saiki-san no mayoko ni ha ketsu maru dashi no Tte sonna koto yori shishou! Dou ka, ore wo deshi ni shite kudasai ssu," yang berarti 'Di sebelah kananmu ada bokong bugil yang ... Daripada itu, Guru, tolong jadikan aku muridmu!.' tuturan tersebut sengaja berhenti ditengah-tengah atau bersifat tidak lengkap, tuturan tersebut menjadi rancu atau tidak jelas, sehingga menimbulkan pertanyaan dari Saiki tentang apa maksud yang dikatakan. Tuturan tersebut menjadi lucu karena Toritsuka sebagai petutur merasa bahwa dirinya terlalu banyak berbicara yang tidak perlu sehingga dia lupa akan tujuan awal dia datang, dia juga menghentikan penjelasannya di tengah-tengah karena keadaan hantu tersebut yang tidak memungkinkan untuk dijelaskan kapada saiki. Toritsuka merasa apa yang dikatakannya diawal berbeda dengan harapannya, harapan awal Toritsuka datang menemui Saiki adalah untuk meminta Saiki menjadi gurunya.

Saiki berharap ucapan yang dikatakan oleh Toritsuka mengenai hantu diselesaikan sampai akhir, namun Toritsuka memotong penjelasan tersebut sehingga saiki merasa kebingungan. Namun dalam tuturan tersebut Toritsuka yang memperkenalkan diri dengan kemauannya sendiri menjelaskan tentang hantu-hantu yang berada di kamar Saiki, dan penjelasan Toritsuka tidaklah sampai akhir dan terpotong ditengah-tengah. Jika Toritsuka hanya berbicara mengenai maksud dan tujuan nya datang kepada Saiki, seperti 'karena aku dengar dari hantu bahwa ada pengguna telekinesis disekitar sini, makanya aku datang untuk menjadikannya seorang guru, karena aku juga memiliki kekuatan yang sama, walaupun hanya untuk 
Eka Triyana, Humor Sebagai Bentuk Pelanggaran Maksim Kerja Sama dalam Animasi Saiki Kusuo No Psinan

berkomunikasi dengan hantu' maka hal tersebut tidaklah memicu humor karena tuturan tersebut sejalan dengan harapan Saiki yang menerima surat.

\section{SIMPULAN}

Setelah melakukan penelitian dari tuturan-tuturan tokoh dalam animasi Saiki Kusuo no Psinan terdapat pelanggaran maksim dalam prinsip kerjasama. Berdasarkan empat macam pelanggaran maksim kerja sama yang ditemukan setelah data diteliti, maka penulis dapat menarik kesimpulan bahwa humor yang terjadi di dalam animasi tersebut terjadi karena situasi inkongruen yang disebabkan oleh pelanggaran maksim kerja sama. Jika tuturan para tokoh di dalam animasi tersebut tidak melanggar prinsip kerja sama dan jawaban serta tuturan yang diberikan sesuai dengan apa yang diekspetasikan, maka tuturan tersebut akan terlihat biasa saja dan tidak terlalu menimbulkan reaksi humor.

\section{DAFTAR PUSTAKA}

Anastasya, Sicilia. (2013). "Teknik-teknik Humor dalam Program Komedi di Televisi Swasta Nasional Indonesia”. Jurnal E-Komunikasi Vol. 1 No. 1.

Ariefandi, F. (2018). Ilokusi yang memberikan efek humor kepada pembaca dalam Azumanga Daioh. LITE: Jurnal Bahasa, Sastra, dan Budaya 14 (2), 118-138.

Prakoso, Ilham Doni. (2017). Wujud Humor yang Ditimbulkan Oleh Pelanggaran Prinsip Kerjasama dalam Anime "Danshi Koukousei No Nichijou" Episode 16 Karya Yasunobu Yamauchi. Semarang: Skripsi Universitas Dian Nuswantoro.

Rahmandji, Didiek. (2007). "Sejarah, Teori, dan Fungsi Humor”. Jurnal Tahun 35, Nomor 2. Malang: Seni dan Desain FS Universitas Negeri Malang.

Rusminto, Nurlaksana Eko. (2010). Memahami Bahasa Anak-anak. Bandar Lampung: Universitas Lampung.

Saifudin, A., Risagarniwa, Y.Y., Citraresmana, E., Sidiq, I.I. (2019). Pengembangan Alat Analisis Humor dalam Komik Jepang. Japanese Research on Linguistics, Literature, and Culture 1 (2), 129-143.

Saifudin, A. (2018). Konteks dalam Studi Linguistik Pragmatik. Lite: Jurnal Bahasa, Sastra, dan Budaya 14 (2), 108-117.

Saifudin, A., Risagarniwa, Y.Y., Citraresmana, E. (2017). Developing a Semiotic Analysis Tool of Humor in Manga: A Pilot Study of Cognitive and Cultural Representation in Humorous Comic. 6 th Global Conference on Business and Social Sciences on "Contemporary Issues in Business and Social Sciences Research" (CIBSSR - 2017). 
Saifudin, A. (2017). Penggunaan Manga Humor dalam Pembelajaran Bahasa dan Penelitian Bahasa Jepang. JAPANEDU: Jurnal Pendidikan dan Pengajaran Bahasa Jepang 2 (2), 99-113.

Saifudin, A. (2005). Faktor sosial budaya dan kesopanan orang Jepang dalam pengungkapan tindak tutur terima kasih pada skenario drama televisi Beautiful Life karya Kitagawa Eriko. Thesis. Universitas Indonesia.

Sentana, Yuli Mahmudah. (2012). Humor Berupa Pelanggaran Maksim Dalam Film Rrrrrr!!! Karya Alain Chabat. Yogyakarta : Skripsi: Universitas Negeri Yogyakarta.

Susanti, Armi., Aibonotika, A., Rahayu, N. (2013). Analisis Humor dalam Komik "Kariage-kun Vol 35" dari Sudut Pandang Pragmatik. Skripsi: FKIP Universitas Riau.

Wijana, I Dewa Putu. (1996). Dasar-Dasar Pragmatik. Yogyakarta: Penerbit Andi.

Wijana, I Dewa Putu. (2004). Kartun. Yogyakarta: Ombak.

Yule, G. (2014). Pragmatik. (Diterjemahkan oleh Indah Fajar Wahyuni). Yogyakarta: Pustaka Pelajar. 